\title{
Associations between estimated fatty acid desaturase activities in serum lipids and adipose tissue in humans: links to obesity and insulin resistance
}

\author{
Eva Warensjö*1, Magdalena Rosell$^{2}$, Mai-Lis Hellenius ${ }^{3}$, Bengt Vessby ${ }^{1}$, \\ Ulf De Faire ${ }^{4}$ and Ulf Risérus ${ }^{1}$
}

Address: ${ }^{1}$ Department of Public Health and Caring Sciences, Clinical nutrition and metabolism, Uppsala University, Uppsala, Sweden, ${ }^{2}$ Department of Biosciences and Nutrition, Karolinska Institutet, Stockholm, Sweden, ${ }^{3}$ Department of Medicine, Clinical Epidemiology Unit, Karolinska Institutet, Stockholm, Sweden and ${ }^{4}$ Institute of Environmental Medicine, Unit of Cardiovascular Epidemiology, Karolinska Institutet, Stockholm, Sweden

Email: Eva Warensjö* - eva.warensjo@pubcare.uu.se; Magdalena Rosell - Magdalena.rosell@ki.se; Mai-Lis Hellenius - mai-lis.hellenius@ki.se; Bengt Vessby - bengt.vessby@pubcare.uu.se; Ulf De Faire - Ulf.defaire@ki.se; Ulf Risérus - ulf.riserus@pubcare.uu.se

* Corresponding author

Published: 27 August 2009

Lipids in Health and Disease 2009, 8:37 doi:10.1186/1476-5IIX-8-37

This article is available from: http://www.lipidworld.com/content/8/I/37

(c) 2009 Warensjö et al; licensee BioMed Central Ltd.

This is an Open Access article distributed under the terms of the Creative Commons Attribution License (http://creativecommons.org/licenses/by/2.0), which permits unrestricted use, distribution, and reproduction in any medium, provided the original work is properly cited.
Received: 29 June 2009

Accepted: 27 August 2009

\begin{abstract}
Fatty acid composition of serum lipids and adipose tissue triacylglycerols (AT-TAG) partly reflect dietary fatty acid intake. The fatty acid composition is, besides the diet, also influenced by desaturating enzymes that can be estimated using product-to-precursor fatty acid ratios. The interrelationships between desaturase indices derived from different serum lipid fractions and adipose tissue are unclear, as well as their associations with obesity and insulin resistance. We aimed to investigate cross-sectional correlations between desaturase indices as measured in serum lipid fractions (phospholipids; PL and free fatty acids; FFA) and in adipose tissue (AT-TAG). In a population-based sample of $30 \mathrm{I}$ healthy 60 -year-old men various desaturase indices were assessed: stearoyl-CoA-desaturase (16:In-7//6:0; SCD-16 and 18:In-9//8:0; SCD-I8, respectively), delta-6desaturase (20:3n-6//8:2n-6; D6D) and delta-5-desaturase (20:4n-6/20:3n-6; D5D). Correlations with BMI and insulin resistance (HOMA-IR) were also examined. SCD-16 and D5D were significantly correlated between fractions and tissues (all $r>0.30$ ), whereas SCD- 18 and D6D were not. Desaturase indices in serum FFA and AT-TAG were significantly correlated; SCD-16 ( $r=$ $0.63)$, SCD- $18(r=0.37)$, and D5D $(r=0.43)$. In phospholipids, SCD- 16 was positively correlated to BMI $(r=0.15)$, while D5D negatively to both BMI $(r=-0.30)$ and HOMA-IR $(r=-0.3 \mathrm{I})$, all $p<$ 0.01 . D6D in both phospholipids and AT-TAG was positively correlated to HOMA-IR and BMI (all $p<0.01$ ). In conclusion, SCD-I and D5D activity indices showed overall strong correlations between lipid pools. SCD-I activity index in adipose tissue is best reflected by $16: 1 / 16: 0$-ratio in serum FFA, but associations with obesity and insulin resistance differ between these pools. D5D in PL was inversely related to obesity and insulin resistance, whereas D6D index showed positive associations.
\end{abstract}




\section{Findings}

The fatty acid composition of serum lipids and adipose tissue triacylglycerols reflect the dietary fat intake over the previous weeks and years, respectively [1-4]. The fatty acids composition is also influenced by desaturating enzymes and lifestyle factors such as smoking and physical activity $[1,5]$. Free fatty acids (FFA) are mainly released from adipose tissue by lipolysis and provide energy to a number of organs and serve as substrate for re-esterification of triacylglycerols [6]. Serum fatty acids and desaturase indices have been related to obesity [7], insulin resistance [8], type-2-diabetes [9] and the metabolic syndrome [10]. Desaturase indices, estimated as product-toprecursor fatty acid ratios, are employed in epidemiological studies. However, little data exist on how these indices relate to each other between different lipid pools and tissues. Accumulating evidence suggest that Stearoyl-CoADesaturase (SCD-1) enzyme activity may be regulated differently in adipose tissue and liver, and its link with insulin resistance and obesity may differ between these pools. The primary aim of the present study was to investigate associations between desaturase indices in serum phospholipids, FFA and adipose tissue triacylglycerols (ATTAG). Secondary, associations between desaturase indices and risk markers were studied.

The study participants, 301 healthy men, were selected from a cohort of 60 year old Swedish men and women. The recruitment procedures and investigations have been previously described $[11,12]$. For the analysis of adipose tissue fatty acids a needle biopsy of subcutaneous adipose tissue was taken from the upper left buttock [13]. Blood samples were collected from the antecubital vein. Serum and adipose tissue samples were stored up to one year ($70^{\circ} \mathrm{C}$ ) before analysis. The fatty acid composition of serum phospholipids, FFA and AT-TAG was measured as previously described [14]. Briefly, the samples were extracted in chloroform, separated by thin-layer -chromatography (this step was not carried out for AT-TAG), transmethylated and then separated by gas liquid chromatography with a system from Hewlett-Packard (Avondale, PA)) on a capillary column (Quadrex, New Heaven, CT, USA). Methyl ester standards (GLC- 68A, Nu Check Prep, Elysian, MN, USA) were used to identify the different fatty acids. Desaturase indices were estimated according to the following: SCD-16: 16:1(n-7)/16:0, SCD-18: 18:1(n-9)/ 18:0, D6D: 20:3(n-6)/18:2 (n-6) and D5D: 20:4(n-6)/ 20:3 (n-6). Insulin resistance was estimated by HOMA-IR (fasting insulin $(\mathrm{mU} / \mathrm{l}) \times$ fasting glucose $(\mathrm{mmol} / \mathrm{l}) / 22.5)$ [15]. The statistical analysis was carried out with the software package STATA (version 8.2; STATA Corporation, TX, USA). Correlations were investigated with Spearman's rank correlation test and the test was significant at $\mathrm{p}<$ 0.05. No imputing for missing data was done.
The baseline characteristics of the study population are presented in Table 1. SCD-16 index was correlated between fractions and tissues and the strongest correlation was not surprisingly established between FFA and ATTAG (Table 2 and the Figure 1). SCD-18 in free fatty acids was significantly correlated to both SCD-18 in phospholipids and AT-TAG. D5D was also correlated between tissues and fraction with the strongest correlation between FFA and AT-TAG. D6D in phospholipids and AT-TAG were correlated. SCD-16 index in phospholipids and ATTAG was positively correlated to BMI, whilst SCD-16 in FFA was surprisingly negatively correlated to the HOMAIR (Table 3). SCD-18 in AT-TAG was positively and in phospholipids negatively correlated to BMI and HOMAIR. SCD-18 in FFA was also positively correlated to BMI.

Table I: Baseline characteristics of the study subjects.

\begin{tabular}{|c|c|c|}
\hline Baseline characteristics & & $\mathrm{N}$ \\
\hline Age (years) & $63(0.7)$ & 301 \\
\hline $\mathrm{BMI}\left(\mathrm{kg} / \mathrm{m}^{2}\right)$ & $25.9(3.1)$ & 301 \\
\hline Total cholesterol $(\mathrm{mmol} / \mathrm{l})$ & $5.9(1.0)$ & 301 \\
\hline LDL-cholesterol (mmol/l) & $3.7(1.0)$ & 301 \\
\hline $\mathrm{HDL}$-cholesterol ${ }^{a}(\mathrm{mmol} / \mathrm{l})$ & $1.6(1.4-1.8)$ & 301 \\
\hline Triacylglycerola $(\mathrm{mmol} / \mathrm{l})$ & I.I (0.8-I.4) & 301 \\
\hline Fasting insulin ${ }^{a}(\mathrm{mU} / \mathrm{l})$ & $5.8(4.2-8.0)$ & 301 \\
\hline Fasting glucose ${ }^{a}(\mathrm{mmol} / \mathrm{l})$ & $4.9(4.6-5.2)$ & 301 \\
\hline HOMA-IR $a$ & I.3 (0.9-I.8) & 300 \\
\hline Tobacco users (\%) & 23 & 301 \\
\hline
\end{tabular}

Adipose tissue desaturase indices

\begin{tabular}{lll}
\hline SCD-16 & $0.36(0.1)$ & 297 \\
SCD-18 & $14.8(3.6)$ & 297 \\
D6D $^{a}$ & $17(14-20) \times 10^{-3}$ & 286 \\
D5D & $2.5(0.6)$ & 286 \\
\hline
\end{tabular}

Free fatty acid desaturase indices

\begin{tabular}{lll}
\hline SCD-16 & $0.15(0.04)$ & 300 \\
SCD-18 & $3.95(0.73)$ & 300 \\
D6D $^{a}$ & $33(23-55) \times 10^{-3}$ & 51 \\
D5D $^{a}$ & $3.1(2.2-4.1)$ & 51 \\
\hline Phospholipid desaturase indices & & \\
\hline SCD-16 & & \\
SCD-18 & $0.02(0.017-0.023)$ & 299 \\
D6D & $0.94(0.12)$ & 299 \\
D5D & $0.15(0.13-0.18)$ & 299 \\
& $3.0(0.71)$ & 299 \\
\hline
\end{tabular}

Mean and standard deviation are presented for normally distributed variables and median and interquartile range $\left(25^{\text {th }}-75^{\text {th }}\right.$ percentiles) for skewed variables.

a Skewed variable

HOMA Homeostasis model insulin resistance

SCD Stearoyl-CoA-desaturase (SCD-16 = 16:1(n-7)/16:0, SCD-18= I8:I(n-9)//8:0)

D5D delta-5-desaturase $(20: 4(n-6) / 20: 3(n-6))$

D6D delta-6-desaturase $(20: 3(n-6) / / 8: 2(n-6))$ 
Table 2: Spearman rank correlations between estimated fatty acid desaturases in serum phospholipids, serum free fatty acids and adipose tissue triacylglycerols.

\begin{tabular}{|c|c|c|c|c|c|c|c|}
\hline & & \multicolumn{3}{|c|}{ Serum free fatty acids } & \multicolumn{3}{|c|}{ Adipose tissue triacylglycerols } \\
\hline & & \multicolumn{3}{|c|}{ SCD-16 } & \multicolumn{3}{|c|}{ SCD-16 } \\
\hline & & $r$ & $P$ & $\mathrm{n}$ & $r$ & $P$ & $\mathrm{n}$ \\
\hline \multirow[t]{4}{*}{ SCD-16 } & $\mathrm{PL}$ & 0.54 & 0.000 & 299 & 0.39 & 0.000 & 295 \\
\hline & FFA & - & - & - & 0.63 & 0.000 & 296 \\
\hline & & \multicolumn{3}{|c|}{ SCD-18 } & \multicolumn{3}{|c|}{ SCD-18 } \\
\hline & & $r$ & $P$ & $\mathrm{n}$ & $r$ & $P$ & $\mathrm{n}$ \\
\hline \multirow[t]{4}{*}{ SCD-18 } & PL & 0.17 & 0.004 & 299 & -0.05 & 0.44 & 295 \\
\hline & FFA & - & - & - & 0.37 & 0.000 & 296 \\
\hline & & \multicolumn{3}{|c|}{ D6D } & \multicolumn{3}{|c|}{ D6D } \\
\hline & & $r$ & $P$ & $\mathrm{n}$ & $r$ & $P$ & $\mathrm{n}$ \\
\hline \multirow[t]{4}{*}{ D6D } & PL & -0.13 & 0.44 & 39 & 0.53 & 0.000 & 295 \\
\hline & FFA & - & - & - & -0.06 & 0.69 & 48 \\
\hline & & \multicolumn{3}{|c|}{ D5D } & \multicolumn{3}{|c|}{ D5D } \\
\hline & & $r$ & $P$ & $n$ & $r$ & $P$ & $n$ \\
\hline \multirow[t]{2}{*}{ D5D } & $\mathrm{PL}$ & 0.31 & 0.03 & 50 & 0.36 & 0.000 & 284 \\
\hline & FFA & - & - & - & 0.43 & 0.002 & 48 \\
\hline
\end{tabular}

SCD Stearoyl-CoA-desaturase (SCD-16 = 16:1(n-7)/16:0, SCD-18 = $18: 1(\mathrm{n}-9) / 18: 0)$

D5D delta-5-desaturase $(20: 4(n-6) / 20: 3(n-6))$

D6D delta-6-desaturase 20:3(n-6)/18:2 (n-6)

PL Serum phospholipids

FFA serum free fatty acids

TAG Triacylglycerols

D5D in phospholipids were negatively associated with BMI and HOMA-IR, whereas D5D of AT-TAG was correlated to neither BMI or to HOMA-IR. D6D in both phospholipids and AT-TAG was positively correlated to HOMA-IR and BMI. The correlation between D5D in phospholipids and D6D in AT-TAG and HOMA-IR remained after adjustment for BMI.

Correlations between desaturase ratios in FFA, PL and ATTAG

This study confirms and extends information regarding desaturase indices in different lipid pools as well as in relation to obesity and insulin action. Estimated SCD-16 and D5D activities were both highly correlated between fraction and tissues, whereas D6D and SCD-18 was not. Associations between serum free fatty acids and AT-TAG for estimated SCD-16, SCD-18 and D5D, were strong and reflects the release of free fatty acids from adipose tissue into the circulation during lipolysis [16]. The correlation between serum free fatty acids and AT-TAG for estimated SCD-16 was the strongest, $r=0.63, p=0.000$. It is possible that the SCD-16 index in FFA to a large part reflect the SCD enzyme activity in adipose tissue, while estimated
SCD in other serum fractions, cholesteryl esters and triacylglycerols, may mainly reflect liver SCD enzyme activity. This is useful information for future epidemiological studies that aim to examine adipose tissue SCD enzyme activity, and differentiate this index from the serum pools mainly reflecting liver SCD activities, i.e. cholesteryl esters, and triacylglycerols [17].

The use of SCD indices derived from phospholipids is however more unclear since there is significant of exchange of fatty acids within systemic circulation between lipid pools [17]. Further it is uncertain which tissue SCD index from phospholipids would reflect. Thus, interpretation of desaturation indices using phospholipids requires caution. To estimate SCD activity of the liver, triacylglycerol is in theory the optimal lipid fraction. Data on this fraction would have been useful to help understand the role of different lipid fractions and its link to liver versus adipose tissue, but were unfortunately not available in the present study. Analyses by Summers et al. [18] of 16:0 and 18:2 n-6 in platelet phospholipids, plasma cholesteryl esters, plasma triacylglycerols and plasma FFA however showed a strong concordance 
Table 3: Spearman rank correlations between estimated desaturase activities in serum phospholipids and adipose tissue triacylglycerols and clinical variables.

\begin{tabular}{cccccccc}
\hline & & \multicolumn{3}{c}{ BMI } & \multicolumn{3}{c}{ HOMA- IR } \\
\cline { 3 - 8 } & & $r$ & $P$ & $n$ & $r$ & $P$ & $n$ \\
\hline \multirow{2}{*}{ SCD-16 } & PL & 0.15 & 0.009 & 299 & 0.08 & 0.17 & 298 \\
& FFA & 0.08 & 0.18 & 300 & -0.16 & 0.006 & 299 \\
& AT-TAG & 0.17 & 0.004 & 297 & -0.02 & 0.78 & 296 \\
& & & & & & & \\
\hline \multirow{2}{*}{ SCD-18 } & PL & -0.31 & 0.000 & 299 & -0.41 & 0.000 & 298 \\
& FFA & 0.15 & 0.009 & 300 & 0.05 & 0.40 & 299 \\
& AT-TAG & 0.35 & 0.000 & 297 & 0.24 & 0.000 & 296 \\
& & & & & & & \\
\multirow{2}{*}{ D6D } & PL & 0.36 & 0.000 & 299 & 0.32 & 0.01 & 298 \\
& FFA & -0.13 & 0.37 & 51 & -.0002 & 1.0 & 51 \\
& AT-TAG & 0.36 & 0.000 & 297 & 0.34 & 0.000 & 296 \\
& & & & & & & \\
\hline \multirow{2}{*}{ D5D } & PL & -0.30 & 0.000 & 299 & -0.31 & 0.000 & 298 \\
& FFA & 0.03 & 0.8 & 51 & -0.16 & 0.27 & 51 \\
& AT-TAG & 0.03 & 0.6 & 286 & -0.04 & 0.46 & 285
\end{tabular}

SCD Stearoyl-CoA-desaturase $(S C D-16=16: 1(n-7) / 16: 0, S C D-18=$ 18:I(n-9)//8:0)

D5D delta-5-desaturase $(20: 4(n-6) / 20: 3(n-6))$

D6D delta-6-desaturase $(20: 3(n-6) / 18: 2(n-6)$

PL Serum phospholipids

AT TAG adipose tissue triacylglycerols

BMI body mass index

HOMA IR Homeostasis model of insulin resistance

between plasma FFA and plasma TG. Such data suggest that several lipid fractions including FFA may reflect liver SCD1 to some extent. Although FFA at first glance should mainly reflect adipose tissue, it is possible that FFA may resemble a combination of adipose tissue SCD1 and liver SCD1, due to exchange of fatty acids between liver and adipose tissue.

It should further be noted that we have not controlled for the potential influence of dietary fatty acids on desaturation indices. Thus, although fatty acid ratios for estimating desaturation activities are meant to reflect enzyme activity other environmental factors including fatty acid intake may influence these ratios [5]. This study investigates the interrelationships between different desaturation indices, rather than exploring what different factors that may determine the level of these desaturation indices.

In the present study, the SCD-18 index in phospholipids and AT-TAG were not correlated. This might be due to endogenous processes such as the elongation of palmitic acid (16:0) to stearic acid (18:0) or the rapid conversion of 18:0 to oleic acid (18:1) [19], or that 18:1 is preferentially retained in adipose tissue [20]. Thus, a high SCD-18 index in serum phospholipids is more influenced by a diet high in 18:1 [21]. However, a high SCD-18 index in AT-
TAG might be related to lipogenesis and therefore related to risk factors in the present study.

\section{Desaturase indices and risk factors $S C D-18$ and SCD- 16}

The SCD index can be estimated as $16: 1 / 16: 0$ or $18: 1 / 18: 0$ and it is the former that has most consistently been related to metabolic complications [22]. When SCD-18 in phospholipids was used in the analyses it was negatively correlated to BMI and HOMA-index, while the relations between SCD-18 in AT-TAG and the same variables were positive, which are difficult results to interpret, but in analogy with the findings in a sub-group of the present study population by Sjögren et al [23]. In that study, the associations between desaturase mRNA expression and desaturase indices in adipose tissue and insulin resistance were investigated. Insulin-resistant subjects had a higher adipose tissue SCD-18, but not SCD-16, compared to insulin-sensitive subjects. This was also found in the present study. It was further suggested that desaturation indices in adipose tissue reflected the expression of SCD, but not of D5D or D6D in adipose tissue [23]. Neither D5D nor D6D indices in FFA correlated to risk factors in the present study, which is compatible with the results of Sjögren et al [23].

\section{SCD-16, D6D and D5D}

Previously, a high SCD-16 and D6D index was associated with obesity [7] and predicted the metabolic syndrome, associations that was confounded by obesity [10]. However, the D5D serum index was inversely related to obesity [7] and the development of the metabolic syndrome, but this association was independent of obesity [10]. A high D5D index in serum phospholipids and muscle has been related to enhanced insulin action in both Pima Indians [24] and Caucasian men [25]. Pan et al. [24] reported D5D index to be independently associated with obesity. The present results extend these previous observations and confirm that the SCD-16 index is primarily related to obesity, but not to insulin resistance, while the D5D index is independently related both to glucometabolic risk and obesity. D6D in phospholipids and AT-TAG were correlated to BMI and insulin resistance, which align with the notion that a high D6D index is associated with risk for the metabolic syndrome [10]. The negative association between SCD-16 in FFA and HOMA-IR is difficult to interpret and may be due to chance and requires further study.

\section{Possible mechanisms}

Desaturases catalyze the synthesis of unsaturated fatty acids that are incorporated into cell membranes which thereby affect permeability and functional properties of cells. This may affect insulin signalling and receptor binding affinities. Besides, long chain polyunsaturated fatty acids synthesized by D5D and D6D may serve as ligands 


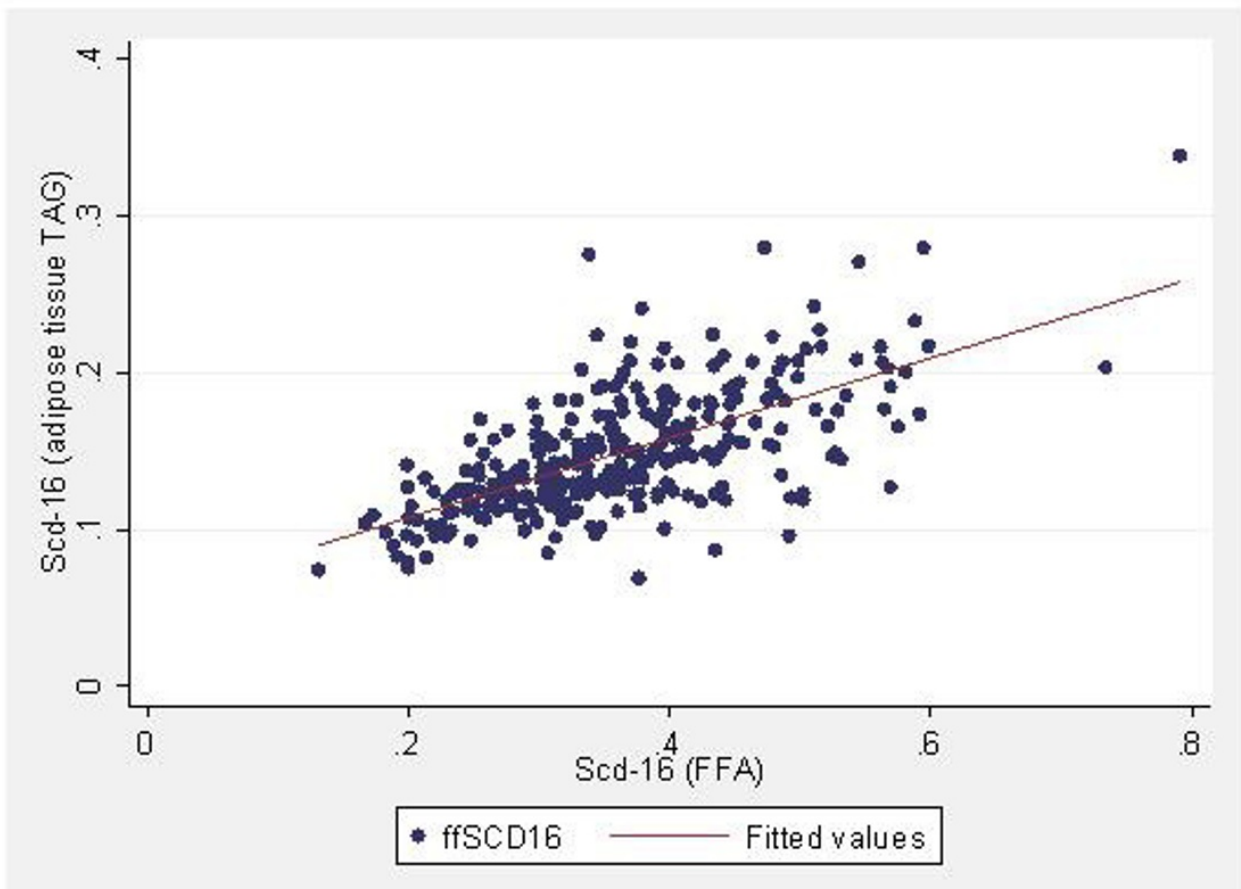

Figure I

Scatter plot showing the relation between SCD-16 (16:1/16:0) estimated in free fatty acids (FFA, $x$-axis) and adipose tissue triacylglycerols (TAG, y-axis).

for transcription factors, such as sterol regulatory element binding protein 1 and peroxisome proliferators activated receptors which interact with genes involved in lipogenesis and fatty acid oxidation. There is also a potential link between D5D and D6D activities and insulin resistance via inflammatory mediators, eicosanoids [20]. The SCD1 enzyme desaturates $16: 0$ and $18: 0$ as a direct result from de novo lipogenesis (DNL) or derived from the diet [17]. In the present population consuming a Western diet with a total fat intake of about 35\% [12], the contribution of fatty acids from DNL is thought to be of lesser importance [26]. It is known that SCD1 activity is up-regulated in the liver in parallel to DNL on a high carbohydrate diet (75E\%) but not at a high fat diet (40E\%) [27]. Relationships between desaturases and insulin resistance may be directed in either direction; either disturbances in desaturases lead to metabolic changes or metabolic changes themselves lead to adaptive changes in desaturating enzymes in order to cope with an aberrant situation.

In conclusion, the SCD-1 and D5D indices showed strong correlations between lipid pools and tissues. We hypothesize that the SCD-16 index in FFA to a large part reflect the SCD enzyme activity in adipose tissue, while the SCD index in triacylglycerols and cholesteryl esters mainly reflect liver SCD enzyme activity. This is useful information to have when studying desaturase indices in epidemi- ological studies. SCD-16 in adipose tissue was related to BMI but not insulin resistance. D5D in phospholipids was inversely related to both these factors and D6D index showed positive associations.

\section{Competing interests}

The authors declare that they have no competing interests.

\section{Authors' contributions}

UR and EW conceived the study and interpreted the data. EW carried out the statistical analyses and drafted the manuscript. UR was also responsible for critical revision and supervision. MR has contributed to data collection and to critical revision of the manuscript. BW was responsible for the fatty acid analyses and interpretation of data and critical revision of the manuscript. MLH and UDF were responsible for data collection, handling of the database, interpretation of data, and critical revision of the manuscript. All of the authors have read and approved the final version of the manuscript.

\section{References}

I. Baylin A, Campos $\mathrm{H}$ : The use of fatty acid biomarkers to reflect dietary intake. Curr Opin Lipidol 2006, I 7(I):22-27.

2. Katan MB, Deslypere JP, van Birgelen AP, Penders M, Zegwaard M: Kinetics of the incorporation of dietary fatty acids into serum cholesteryl esters, erythrocyte membranes, and adipose tissue: an 18-month controlled study. J Lipid Res 1997, 38(10):2012-2022. 
3. Ma J, Folsom AR, Shahar E, Eckfeldt JH: Plasma fatty acid composition as an indicator of habitual dietary fat intake in middleaged adults. The Atherosclerosis Risk in Communities (ARIC) Study Investigators. Am J Clin Nutr 1995, 62(3):564-57I.

4. Glatz JF, Soffers AE, Katan MB: Fatty acid composition of serum cholesteryl esters and erythrocyte membranes as indicators of linoleic acid intake in man. Am J Clin Nutr 1989, 49(2):269-276.

5. Vessby B, Gustafsson IB, Tengblad S, Boberg M, Andersson A: Desaturation and elongation of Fatty acids and insulin action. Ann N Y Acad Sci 2002, 967: 183-195.

6. Frayn KN, Tan GD, Karpe F: Adipose tissue: a key target for diabetes pathophysiology and treatment? Horm Metab Res 2007, 39(10):739-742.

7. Warensjö E, Öhrvall M, Vessby B: Fatty acid composition and estimated desaturase activities are associated with obesity and lifestyle variables in men and women. Nutr Metab Cardiovasc Dis 2006, 16(2): 128-136.

8. Vessby B, Tengblad S, Lithell H: Insulin sensitivity is related to the fatty acid composition of serum lipids and skeletal muscle phospholipids in 70-year-old men. Diabetologia 1994, 37(10): 1044-1050.

9. Wang L, Folsom AR, Zheng ZJ, Pankow JS, Eckfeldt JH: Plasma fatty acid composition and incidence of diabetes in middle-aged adults: the Atherosclerosis Risk in Communities (ARIC) Study. Am J Clin Nutr 2003, 78(I):91-98.

10. Warensiö E, Riserus U, Vessby B: Fatty acid composition of serum lipids predicts the development of the metabolic syndrome in men. Diabetologia 2005, 48( ( 0):1999-2005.

II. Rosell MS, Hellenius ML, de Faire UH, Johansson GK: Associations between diet and the metabolic syndrome vary with the validity of dietary intake data. Am J Clin Nutr 2003, 78(I):84-90.

12. Rosell M, Johansson G, Berglund L, Vessby B, de Faire U, Hellenius ML: Associations between the intake of dairy fat and calcium and abdominal obesity. Int J Obes Relat Metab Disord 2004, 28(II): I 427-I 434.

13. Beynen AC, Katan MB: Rapid sampling and long-term storage of subcutaneous adipose-tissue biopsies for determination of fatty acid composition. Am J Clin Nutr 1985, 42(2):3 I 7-322.

14. Boberg M, Croon LB, Gustafsson IB, Vessby B: Platelet fatty acid composition in relation to fatty acid composition in plasma and to serum lipoprotein lipids in healthy subjects with special reference to the linoleic acid pathway. Clin Sci (Lond) 1985, 68(5):58I-587.

15. Matthews DR, Hosker JP, Rudenski AS, Naylor BA, Treacher DF, Turner RC: Homeostasis model assessment: insulin resistance and beta-cell function from fasting plasma glucose and insulin concentrations in man. Diabetologia 1985, 28(7):412-419.

16. Stich $\mathrm{V}$, Berlan M: Physiological regulation of NEFA availability: lipolysis pathway. Proc Nutr Soc 2004, 63(2):369-374.

17. Hodson L, Skeaff CM, Fielding BA: Fatty acid composition of adipose tissue and blood in humans and its use as a biomarker of dietary intake. Prog Lipid Res 2008, 47(5):348-380.

18. Summers LK, Fielding BA, Bradshaw HA, llic V, Beysen C, Clark ML, Moore NR, Frayn KN: Substituting dietary saturated fat with polyunsaturated fat changes abdominal fat distribution and improves insulin sensitivity. Diabetologia 2002, 45(3):369-377.

19. Kris-Etherton PM, Griel AE, Psota TL, Gebauer SK, Zhang J, Etherton TD: Dietary stearic acid and risk of cardiovascular disease: intake, sources, digestion, and absorption. Lipids 2005, 40(12): I 193-1200.

20. Nakamura MT, Nara TY: Structure, Function, And Dietary Regulation of Delta6, Delta5, and Delta9 Desaturases. Annu Rev Nutr 2004, 24:345-376.

21. Vessby B, Uusitupa M, Hermansen K, Riccardi G, Rivellese AA, Tapsell LC, Nalsen C, Berglund L, Louheranta A, Rasmussen BM, et al.: Substituting dietary saturated for monounsaturated fat impairs insulin sensitivity in healthy men and women: The KANWU Study. Diabetologia 200I, 44(3):3।2-319.

22. Vessby B: Dietary fat, fatty acid composition in plasma and the metabolic syndrome. Curr Opin Lipidol 2003, I 4(I):I5-19.

23. Sjogren P, Sierra-johnson J, Gertow K, Rosell M, Vessby B, de Faire $U$, Hamsten A, Hellenius ML, Fisher RM: Fatty acid desaturases in human adipose tissue: relationships between gene expression, desaturation indexes and insulin resistance. Diabetologia 2008, 5 I (2):328-335.
24. Pan DA, Lillioja S, Milner MR, Kriketos AD, Baur LA, Bogardus C, Storlien LH: Skeletal muscle membrane lipid composition is related to adiposity and insulin action. J Clin Invest 1995, 96(6):2802-2808.

25. Borkman M, Storlien LH, Pan DA, Jenkins AB, Chisholm DJ, Campbell LV: The relation between insulin sensitivity and the fatty-acid composition of skeletal-muscle phospholipids. N Engl J Med 1993, 328(4):238-244.

26. Frayn KN: Metabolic Regulation -A human perspective. Second edition. Oxford, UK: Blackwell Science Ltd; 2003.

27. Chong MF, Hodson L, Bickerton AS, Roberts R, Neville M, Karpe F, Frayn KN, Fielding BA: Parallel activation of de novo lipogenesis and stearoyl-CoA desaturase activity after $3 \mathrm{~d}$ of high-carbohydrate feeding. Am J Clin Nutr 2008, 87(4):817-823.
Publish with Bio Med Central and every scientist can read your work free of charge

"BioMed Central will be the most significant development for disseminating the results of biomedical research in our lifetime. "

Sir Paul Nurse, Cancer Research UK

Your research papers will be:

- available free of charge to the entire biomedical community

- peer reviewed and published immediately upon acceptance

- cited in PubMed and archived on PubMed Central

- yours - you keep the copyright 